\title{
In memory of Professor Valery Savchenko January 8, 1952 - July 25, 2021
}

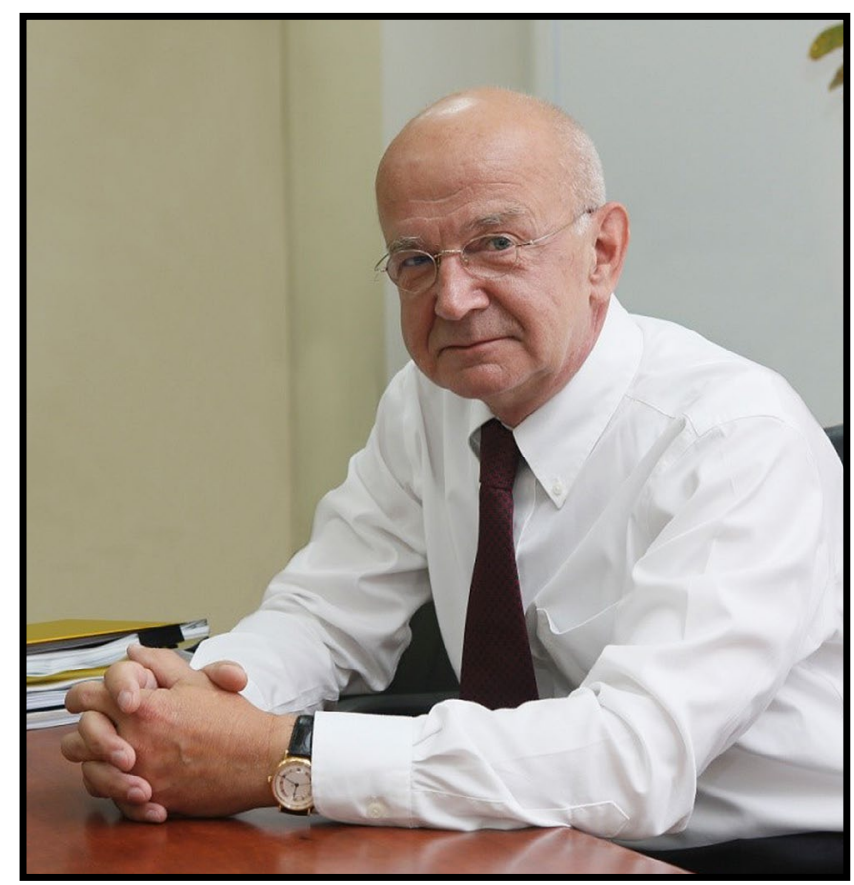

Russian hematology has lost an esteemed leader, Professor Valery G. Savchenko who died suddenly on 25 July 2021. He was an outstanding physician, scientist and researcher. He headed the National Medical Research Center of Hematology, was Chief Hematologist of the Russian Health Ministry, President of National Hematology Society and Academician of the Russian Academy of Sciences. For many years he was responsible for advancing hematology in the USSR and later Russia.

Valery Savchenko was born in the Ukraine on 8 January, 1952. After graduation from the $2^{\text {nd }}$ Moscow Physical and Mathematical School at Moscow University in 1969, he studied medicine at the $1^{\text {st }} I$. Sechenov Moscow Medical Institute graduating with distinction in 1975.

His life in medicine and research was devoted to hematology. In 1980, he completed his residency and postgraduate studies at the Department of Hematology and Intensive Care at the Central Institute of Postgraduate Education where he presented his MD thesis: Pathogenesis and treatment of idiopathic thrombocytopenic purpura. Thereafter, he joined the faculty as an Assistant Professor. In 1988, Dr. Savchenko moved with his mentor Prof. Andrei I. Vorobiov to the Research Centre for Hematology where he was appointed Head of the Hemoblastoses Chemotherapy and Bone Marrow Transplantation Department. In 1993, he presented his doctoral thesis: Modern strategy for acute leukemia therapy.
Dr. Savchenko was awarded the title of Full Professor in 1996. In 2011, he assumed the position of Director of the Hematology Research Centre, now National Medical Research Centre for Hematology of the Russian Ministry of Health. In 2004, he was elected a Corresponding Member of Academy of Medical Sciences, and in 2013 he became Academician of the Russian Academy of Sciences.

His inquiring mind, encyclopaedic knowledge and analytical thinking allowed him to excel in many areas of modern hematology. Prof. Savchenko was able to set forth distinct scientific tasks and resolve them, suggesting the direction of diagnostic evaluations and developing therapy algorithms. He evolved therapy protocols for acute leukemias and bone marrow failure disorders, headed the first Russian multicentre studies, and, along with Prof. Boris Afanasyev, established and advanced hematopoietic cell transplants in the USSR and Russia.

Prof. Savchenko lead many studies in molecular genetics, biology, physiology of hematopoiesis, cytogenetics and transplant immunology and edited the Russian national guidelines for diagnosis and treatment of blood diseases. He had many pupils, several of whom are now leaders of hematology in Russia. Prof. Savchenko advised $30 \mathrm{PhD}$ and 14 doctoral dissertations. He held or co-held 14 patents. He was very concerned with hematology education in Russia, was permanently engaged in educational activities and participated in interdisciplinary conferences.

Prof. Savchenko was Editor-in-Chief of Hematology and Transfusiology and on the Editorial Board of several academic journals including Therapeutic Archive, Hematology. Transfusiology Eastern Europe, Cellular Therapy and Transplantation, and Biological Products. Prevention, Diagnosis, Treatment.

Prof. Savchenko was a member of the World Committee of the International Association for Comparative Research on Leukemia and Related Diseases (IACRLRD) which he joined in the early 1990s on invitation by Prof. Rolf Neth and was on the World Committee as a Russian representative from 1997-2007 and again from 2015 onwards. In 2019, he was re-elected to serve on the World Committee until 2023. In 2021, he was invited to head as president the $31^{\text {st }}$ IACRLRD symposium in Moscow in 2023.

Prof. Savchenko promoted participation of his Hematological Centre in the European LeukemiaNet (ELN); his institution becoming one of the six initial Russian ELN-participants. In 2011, he gave the ELN-keynote lecture on acute myeloid leukemia. His group continues to be a strong partner of cooperative leukemia research within ELN. 
Analytical mind, soft speech and cautious humour of Prof. Savchenko's are unforgettable. He is survived by his wife and long-term collaborator, Prof. Elena Parovichnikova, an internationally renowned hematologist, his son and daughter, Pavel and Sofia and grandchildren.
There are people that are hard to replace, and Savchenko was among them. We are reminded of the proverb: Death is a giant against whom even the Tsars must draw weapons. The loss is immense.

Alexander D. Kulagin, Prof., Director, RM Gorbacheva Memorial Research Institute of Pediatric Oncology, Hematology and Transpantation, Pavlov University, St. Petersburg, Russia

Rüdiger Hehlmann, Prof. Dr., Dr. h.c, Med. Fakultät Mannheim, Heidelberg University, Germany

Robert Peter Gale, Visiting Prof., Dr., DSc h.c., Hematology Research Centre, Imperial College London, London, UK

Axel R. Zander, Prof. Dr. Dr. h.c., University Medical Center Hamburg-Eppendorf, Germany

Boris Fehse, Prof. Dr., Hamburg University, Germany

\section{Памяти профессора Валерия Григорьевича Савченко 8 января 1952 года - 25 июля 2021 года}

Российская гематология потеряла всеми уважаемого лидера - профессора Валерия Савченко, который скоропостижно скончался 25 июля 2021 г. Он был выдающимся врачом, ученым и исследователем, возглавлял Национальный медицинский исследовательский центр гематологии России, был главным внештатным гематологом министерства здравоохранения РФ, президентом Национального гематологического общества и академиком Российской академии наук. На протяжении многих лет он отвечал за развитие гематологии в СССР и, позже - в России.

Валерий Григорьевич Савченко родился 8 января 1952 года на Украине. После окончания в 1969 году второй московской физико-математической школы при МГУ, он поступил в 1-й Московский медицинский институт им. И.М.Сеченова, который с отличием закончил в 1975 г.

Его жизнь в медицине и науке была посвящена гематологии. В 1980 г. В.Г. Савченко окончил ординатуру и аспирантуру на кафедре гематологии и интенсивной терапии Центрального института усовершенствования врачей, защитив кандидатскую диссертацию на тему «Патогенез и лечение идиопатической тромбоцитопенической пурпуры», затем в течение 7 лет работал ассистентом кафедры. В 1988 г. В.Г. Савченко, со своим учителем, профессором А.И. Воробьевым перешел в гематологический научный центр Минздрава СССР, где был назначен заведующим отделением химиотерапии гемобластозов и трансплантации костного мозга. В 1993 г. защитил докторскую диссертацию по теме «Современная стратегия терапии острых лейкозов». Ученое звание профессора было присвоено ему в 1996 г.
В 2011 г. В.Г. Савченко был назначен Генеральным директором ФГБУ «Гематологический научный центр» Минздрава России (ныне - ФГБУ «Национальный медицинский исследовательский центр гематологии» Минздрава России). В 2004 г. он был избран членом-корреспондентом академии медицинских наук, а в 2013 г. академиком Российской академии наук.

Его пытливый ум, энциклопедические знания и аналитическое мышление позволили ему добиться превосходных результатов во многих областях современной гематологии. В.Г. Савченко мог четко сформулировать конкретные научные задачи и решать их, подсказать направление диагностического поиска и разработку алгоритмов лечения. Он разрабатывал программы терапии острых лейкозов и депрессий кроветворения, руководил проведением первых в России многоцентровых исследований в этой области и, наряду с профессором Б.В. Афанасьевым, был у истоков внедрения и совершенствования трансплантации костного мозга в СССР и России.

Профессор Савченко руководил многими исследованиями в области молекулярной генетики, биологии, физиологии кроветворения, цитогенетики и трансплантационной иммунологии. Под его руководством были разработаны национальные алгоритмы диагностики и лечения заболеваний системы крови. У него было множество учеников, некоторые из которых теперь являются лидерами российской гематологии. Под руководством В.Г. Савченко защищено 30 кандидатских и 14 докторских диссертаций. Он является соавтором 14 авторских свидетельств на изобретения. Уделяя большое внимание сохранению школы в подготовке врачей- 
гематологов, он постоянно занимался преподавательской деятельностью и участвовал в междисциплинарных консилиумах.

В.Г. Савченко являлся главным редактором журнала «Гематология и трансфузиология», входил в состав редколлегии журналов «Терапевтический архив», «Гематология. Трансфузиология. Восточная Европа», членом редакционного совета журналов «Cellular Therapy and Transplantation», «Биопрепараты. Профилактика, диагностика, лечение».

Профессор Савченко был членом Всемирного комитета Международной ассоциации сравнительного изучения лейкозов и родственных заболеваний (МАСИЛР), в которую он вошел в начале 1990-х гг. по приглашению профессора Рольфа Нета и представлял Россию во Всемирном комитете с 1997 по 2007 г. и далее - с 2015 г. В 2019 г. он был переизбран во Всемирный комитет по 2023 г. В 2021 г. он был приглашен в качестве президента 31-го симпозиума МАСИЛР в Москве (2023 г).
В.Г. Савченко развивал участие своего Центра гематологии в работе European LeukemiaNet (ELN), его организация стала одним из 6 первых российских участников ELN. B 2011 г. он прочел основную лекцию об остром миелоидном лейкозе на конгрессе ELN. Его группа продолжает вносить весомый вклад в кооперативные исследования по лейкозам, проводимые ELN.

Аналитический ум В.Г. Савченко, его мягкая речь и сдержанный юмор незабываемы. Мы выражаем соболезнования его жене и многолетнему соратнику - профессору Елене Паровичниковой, известному в мире гематологу, его сыну Павлу, дочери Софье, и внукам.

Есть люди, которых трудно заменить, Валерий Григорьевич Савченко был одним из них. Пословица гласит: Смерть - великан, против которого даже цари должны обратить оружие. Эта утрата огромна.

Александр Д. Кулагин, проф., директор НИИ детской онкологии, гематологии и трансплантологии им. Р. М. Горбачевой, Санкт-Петербургский государственный медицинский университет им. И. П. Павлова, Санкт-Петербург, Россия

Рюдигер Хельманн, проф., почетный доктор, Медицинский факультет Манхайм, Гейдельбергский университет, Германия

Роберт Питер Гэйл, проф., доктор, приглашенный профессор, почетный доктор, Центр гематологических исследований, Имперский колледж, Лондон, Соединенное Королевство

Аксель Цандер, проф., почетный доктор, Университетский медицинский центр Гамбург-Эппендорф, Гамбург, Германия

Борис Фезе, проф., доктор, Гамбургский университет, Германия 